\title{
O BUGRE, UM JOÃO-NINGUÉM um personagem brasileiro
}

\author{
Luís Augusto De Mola Guisard \\ Professor de Sociologia da UNIFMU e Unifieo, Analista da Fundação Seade
}

$\mathrm{A}$ forma pela qual a sociedade constrói e reconstrói permanentemente uma imagem negativa de um certo grupo, neste caso os designados pela palavra "bugre", inspirou o sentimento que está na origem deste artigo. ${ }^{1}$

É curioso observar que pequenas realidades regionais em grotões escondidos do Brasil contemporâneo possam retratar e refletir elementos da formação de uma história que remete à longínqua Idade Média, aos valores e rituais da Igreja Católica de então; aos movimentos heréticos, no século IX na Bulgária e no século VII na Ásia Menor; curiosamente, a práticas sodomitas durante um longo período na passagem da Idade Média para a Moderna na Europa Ocidental; a diversas outras consideráveis influências e a realidades mais recentes com os jesuítas e o capitalismo aventureiro e saqueador da colonização portuguesa. Aglutinando em torno de si uma bagagem bastante antiga, de influências diversas, sempre com conotação negativa sob a ótica vigente, está o termo, o personagem "bugre".

$\mathrm{O}$ termo bugre originou-se num movimento herético, na Europa, durante a Idade Média, representando uma força contrária aos preceitos ditados pela ortodoxia da Igreja. Surgiu no século IX, na Bulgária, tendo sido batizado como bogomilismo, ${ }^{2}$ inspirado no nome do padre Bogomil, considerado fundador da seita herética.

Os bogomilos eram também conhecidos como maniqueus, no Império Bizantino, como cátaros, palavra grega que significa os puros, e genericamente como albigenses, para designar os heréticos em geral. Sua origem está diretamente relacionada ao paulacianismo, ${ }^{3}$ movimen- to herético do século VII que se desenvolveu na Ásia Menor.

Há indicações bibliográficas ${ }^{4}$ que remetem a origem do termo bugre ao Oriente, presente entre os eslavos, sendo posteriormente incorporada ao mundo católico.

A doutrina dos bogomilos nega o mundo terreno e tudo que é matéria, pois esta é criação do Diabo, artífice da natureza, que se encontra em todos os homens; nega os rituais da Igreja Católica, os sacramentos, o matrimônio, o batismo, a liturgia, os ornamentos e a cruz. Os adeptos dessa doutrina não comiam carne, confessavam-se e absolviam-se entre si, constituindo uma comunidade fechada em si mesma, auto-suficiente e questionadora dos valores morais e religiosos vigentes. Eles não aceitavam nem mesmo a veneração da cruz, porque era de matéria perecível; e tudo aquilo que tem este caráter perecível era também recusado.

Aos poucos, no Mundo Ocidental, o sentido da palavra bugre vai se transportando de um mundo religioso para um mundo profano, levando consigo a idéia do bugre como o devasso, o sodomita, o pederasta, o infiel em que não se pode confiar, que representa a porção mais baixa da sociedade européia.

Diversas fontes da literatura européia ocidental (portuguesas, francesas, italianas) trazem a tradução do termo bugre sempre associado a conceitos ofensivos, à sodomia, à heresia. Finalmente, este termo vem a ser associado aos índios encontrados na América e, simultaneamente, no Brasil.

No Brasil, os costumes dos índios, os hábitos alimentares, o fato de andarem nus, a cor da pele, os traços faciais, 
a "imoralidade" e a relação com o meio ambiente seriam vistos como sinais de proximidade ou mesmo plena imersão na natureza, configurando uma pré-humanidade que mal se distingue da animalidade - esta entendida como prova da privação das luzes da fé religiosa.

Por mais que as imagens que representavam estes indivíduos para os portugueses proviessem inteiramente de uma matriz cultural cristã, é também certo que aqueles povos apareciam como inteiramente estranhos, com seus costumes exóticos, vivendo num ambiente desconhecido, falando uma língua incompreensível. Todas as marcas de estranheza não impediram contudo a utilização do termo bugre, tão familiar aos europeus há muito tempo.

A visão da proximidade com a natureza vinha acompanhada da visão de "maléficos poderes secretos" e do "retorno dos mortos", experiência arcaica cujos traços não foram completamente anulados. O bugre parece despertar lembranças arcaicas de algo já vivenciado pelos cristãos de outrora, que viam nos bogomilos a crença no poder desmesurado do Diabo, a execração dos costumes, a recusa a rituais, a opção pela pobreza, a negação do matrimônio e a decorrente devassidão como que reatualizados pelos indígenas. Assim, tal como na Idade Média, o bugre, como designação dos nossos indígenas, é associado outra vez à sodomia. "A denominação de bugres dada pelos portugueses aos indígenas do Brasil em geral e a uma tribo de São Paulo em particular talvez exprimisse o horror teológico de cristãos mal saídos da Idade Média ao pecado nefando, por eles associado sempre ao grande, ao máximo de incredulidade ou heresia. Já para os hebreus o termo gentio implicava idéia de sodomia; para o cristão medieval foi o termo bugre que ficou impregnado da mesma idéia pegajosa do pecado imundo. Quem fosse herege era logo havido por sodomita; como se uma danação arrastasse inevitavelmente à outra" (Freyre, 1963:178).

A sodomia não era apenas uma imagem associada à palavra bugre, mas objeto de investigação inquisitorial, conforme testemunho de Freyre (1963:178): "Por crime de sodomia aparecem, no fim do século XVI, perante o visitador do Santo Ofício, vários indígenas e mamelucos: homens ainda mal cristianizados, católicos ainda meio crus. A Igreja fulminou neles como pecado dos mais profundos - um dos quatro clamantia peccata da Teologia da Idade Média - o que para a moral sexual desses primitivos - dos selvagens que o Padre Cardim ouvindo em confissão achara tão cândidos - seria quando muito um pecadilho. Parece, entretanto, que a mentalidade portu- guesa cedo identificou os indígenas com a prática da pederastia; prática para os cristãos tão abominável."

O espírito de um capitalismo saqueador e aventureiro do colonizador português confrontou-se com as idéias e vivências das tribos indígenas do Brasil em relação ao trabalho e ao que disto decorre, o que significou um abismo cultural.

Desta forma, o termo bugre vai reaparecendo na lembrança do europeu, com uma identidade já construída, acompanhando a idéia da infidelidade moral, porém com novos elementos, próprios da nova situação. Estes novos elementos, já sugeridos entre os bogomilos no fim da Idade Média, vão ganhando maior importância com o desenvolvimento do capitalismo mercantil, deixando cada vez mais ampla e fluida a identificação do bugre dada pelo outro.

O bugre é também um personagem do meio rural brasileiro que aparentemente não possuiria uma história de tão longo fôlego, de tão "tradicional" origem, se é que se pode chamar de tradicional a um fato ou personagem que se originou já há muito no seio da humanidade, antes mesmo da descoberta do Brasil para o mundo "civilizado", e cuja memória vem sendo transmitida ao longo de pelo menos 11 séculos, desde os bogomilos no século IX. Os bugres surgiram de uma sociedade muito fechada e de fundamentação radicalmente religiosa. Não parece verossímil uma história tão complexa e antiga para um personagem alcunhado e tratado, hoje, em diversas cidades do Brasil, como "João-Ninguém".

\section{A EXCLUSÃO DO BUGRE NA PRÁTICA COTIDIANA}

Este artigo é resultado de um trabalho (Guisard, 1996) que se originou na cidade mato-grossense de Cáceres, movido pela curiosidade que provocava aquele indivíduo serviçal, considerado "menos inteligente", escravizado em alguns casos ainda, já no encerramento do século XX. Na pesquisa produzida em 1993, foram realizadas entrevistas e discussões em grupo com a comunidade, abrangendo tanto a área urbana quanto a rural que faz fronteira com a Bolívia. Este estudo objetivou conhecer as imagens que a população cacerense tem do bugre pantaneiro e também as que este tem de si próprio.

No convívio diário com a população cacerense, é perceptível o uso freqüente do termo "bugre" como desqualificador de uma parcela considerável da população, tanto no ambiente urbano quanto no rural: "bugre é o que 
vive no mato"; "o bugre é preguiçoso"; "o bugre, você não pode confiar nele, não"; "o bugre é inferior". O ambiente rural parecia ser o ponto de origem da designação, que se estendia ao centro urbano da cidade. Os bugres eram indivíduos com características indígenas, sugerindo uma origem distante dos centros urbanos.

O termo era usado principalmente nos espaços públi$\cos$ - especialmente em referência àqueles que possuíam características específicas ligadas a uma tradição indígena da região - mas poderia ser usado também em espaços mais reservados. Fica claro que o termo é pejorativo, para identificar aqueles que apresentam alguns traços físicos específicos - "cabelo de flecha, liso, escorrido"; "olho rasgado, nariz meio achatado"; "escuro sem ser negro" que estão associados a aspectos culturais, sociais, psíquicos e econômicos também específicos: "o bugre é rústico, atrasado"; "o bugre verdadeiro é do mato, aquele que está escondido, mais agressivo e arredio"; "o bugre que está na cidade é mais dócil, pode ser trabalhador, mas é traiçoeiro".

Os grupos tradicionais de Cáceres, bem como imigrantes e migrantes, naturais de diversas regiões do país e os próprios indivíduos designados como "bugres", sentiamse mais ou menos à vontade para pronunciar a palavra bugre em variados contextos.

A partir desse momento, há um interesse não só pelo termo bugre e seu portador, mas também pelo contexto social global em que este "tipo" está inserido, ou seja, pela sociedade cacerense.

Há em Cáceres um número considerável de famílias tradicionais, uma espécie de elite local que, apesar de ter perdido em parte a hegemonia econômica, conserva ainda, pelo prestígio, poder político e social, exibindo nas relações sociais signos de autoridade, herança de um passado em que o exercício da dominação era determinante de sua posição social. Verifica-se, também, a existência de famílias de classe média, de origem mais recente, mas não menos autoritária, depurando a violência de suas características mais visíveis nas relações de mando e obediência. Esta classe média, constituída sobretudo de migrantes de outros estados, de alguma forma levou para a região um novo padrão de sociabilidade, com elementos autoritários associados a elementos democráticos. Este novo padrão inspira um questionamento da relação autoritária já petrificada no interior da sociedade cacerense.

Esta sociedade começa a ter que conviver com uma nova dinâmica interna em suas relações interpessoais, agora mais abrangentes.
A presença recente dos migrantes (paulistas, mineiros, paranaenses, gaúchos, desde a década de 60 , principalmente) despertou um sentimento de fragilidade perante os valores tradicionais autoritários. Esta insegurança, este medo, esta angústia manifestam-se, dentre outras formas, na retomada do preconceito contra o bugre, que figura como bode expiatório para tudo o que é tido como negativo, indesejável e condenável.

Assim, fica no ar uma impressão de que o autoritarismo, tantas vezes apontado como constitutivo da sociedade brasileira, encontra na figura do bugre uma forma precisa de se manifestar.

É possível estabelecer três expressivas matrizes para se compreender as significações ligadas ao termo bugre: religiosa, moderna e biológica. Essas matrizes dispõemse em camadas de significações sucessivas no tempo, mas as posteriores não eliminam as anteriores, acrescentando-se umas às outras ao longo da história. Assim, a matriz religiosa fornece significados precisos: heregesodomita e infiel-traiçoeiro. Pode-se dizer que os significados mais antigos - o de herege e sodomita - desapareceram na atualidade enquanto conteúdos determinados, mas a desqualificação absoluta que aqueles termos contêm ainda permanece. As significações de infiel e traiçoeiro podem hoje ser encontradas. Na matriz "moderna", ligada às novas práticas econômicas e políticas da modernidade, encontram-se os pares preguiçoso-vagabundo e estrangeiro-inteiramente outro. As significações devidas a uma matriz biológica - deficiente-incapaz e violento-desordeiro - também estão presentes no imaginário sobre o bugre na sociedade cacerense.

A matriz religiosa-moral do termo bugre significa o herege, o vil, o depravado, o sodomita, ser abjeto, ${ }^{5}$ imagens que apontam para um abismo moral que o separa da virtude, da fé e da verdade cristã. Curiosamente, esta distância moral combina-se com a distância espacial: o bugre, de alguma forma, é aquele que está longe, geograficamente, da verdadeira Igreja, a Apostólica Romana.

$\mathrm{O}$ traço herege-sodomita abre caminho para as imagens negativas próprias da idade moderna, marcadas por mudanças profundas de toda ordem, solicitando, desta forma, um novo tipo de homem e sociedade, no que se refere ao seu comportamento e atitude diante da vida.

$\mathrm{O}$ bugre não será visto como o modelo de homem do novo tempo; muito pelo contrário, ele carrega um estigma de épocas passadas de ser identificado como pertencente a uma parcela mais humilde das populações, mais próximas da natureza, carregando consigo todo tipo de 
desvios morais determinados pela história, refletindo ou mesmo resultando numa exclusão social, que ficará mais acentuada com o desenvolvimento do capitalismo e suas exigências.

No processo moderno de laicização e racionalização generalizado, é possível compreender a substituição gradativa dos parâmetros morais-religiosos antigos fundados na oposição Bem e Mal desdobrados em alma e corpo, virtude e vício, graça e pecado, pelo parâmetro moderno de saúde e doença, do normal e do patológico, aliás como formas precisas em que se opõem também a ordem e a desordem.

A partir da Idade Moderna, marcada pelo enfraquecimento do catolicismo, pelo desenvolvimento da ciência e pelo aparecimento de novos modos de produção (Bruni, 1989a:185-186), os bugres, além de serem associados à ralé e ao promíscuo, serão associados parcialmente à desordem e à inferioridade biológica e deverão, desta forma, ser moldados a uma moral que vai se tornando cada vez mais laica, preocupando-se em aproximar o diferente do normal para poder melhor submetê-lo às suas normas e valores. A discussão sobre a imagem do bugre pode ser aproximada ao tema do normal e do patológico. O normal, representado pela razão, pela família, pela unidade, pela homogeneidade, pela civilização, pela sociedade, pelo homem branco, submete o patológico representado pelo diferente, pelo anormal, pelo que foge à regra, pelo bugre, pelo não-branco.

Para a família cacerense tradicional, a sociedade local é vista como um todo coeso, harmonioso e unitário, representada pelos de dentro, pela irmandade das famílias tradicionais e, portanto, o bugre é considerado o ser não integrado, o de fora, o chiquitano, o diferente, aquele que possui traços físicos e culturais dos Bororós e que deverá estar a serviço da norma. "A idéia fundamental é a de que não há diferença de natureza entre o estado normal e o estado patológico em qualquer ser vivo, apenas diferença de grau, de intensidade; o patológico é variação do normal. A doença constitui uma espécie de experimentação espontânea do organismo, a fim de que se compreenda melhor o que seja a saúde" (Bruni, 1989a:177).

Com uma postura extremamente etnocêntrica, o homem de hoje, que vive em sociedades capitalistas, num "processo de diferenciação social e estilização da vida", é aquele que não possui a realidade das coisas, mas sim imagens irreais ou mesmo invertidas da realidade. Há o mundo das paixões, dos preconceitos e das discriminações, no qual não existe lugar para o entendimento e o conhecimento das coisas. "É preciso sempre conservar presente a idéia de que os dados impressionais que têm por função perfilar a cor, a superfície, a forma (isto é, que têm por função representar) são por princípio radicalmente distintos da cor, da superfície, ou da forma, em suma, de todas as qualidades da coisa" (Sartre, 1964:111).

Cáceres, região de tradição rural, atingiu um crescimento urbano mínimo, para atrair levas de migrantes de diversas regiões do país, mostrando que, mesmo estando afastada dos grandes centros urbanos, é fortemente influenciada por estes, no que se refere aos ideais de desenvolvimento e de progresso.

Desta forma, há um conflito entre o tradicional e o moderno, entre o rural e o urbano e, em última instância, entre a natureza e a civilização, onde o bugre é submetido a uma discriminação muito grande, pois, neste conflito, ele sempre foi identificado com a natureza, ou seja, com o lado que o homem sempre desejou dominar, principalmente na Idade Moderna, período da história humana em que começa definitivamente o emprego da razão para a explicação, o desenvolvimento e o controle da natureza.

É na Idade Moderna que ocorre a separação entre os instintos, as paixões e a razão, prevalecendo esta sobre os instintos, que deverão ser aprisionados e dominados para se tornarem úteis a um mundo cada vez mais racional. O bugre pantaneiro é um representante da natureza que deve ser aprisionado, controlado e dominado para servir melhor e sem resistências à mecânica capitalista de produção. Sob o domínio da norma, o patológico tem que se submeter a uma moral laica que irá "nos traçar a imagem do homem que devemos ser" (Fernandes, 1994:52).

Mesmo na Cáceres mais tradicional, na qual ocorre uma proximidade entre as pessoas, o bugre é colocado como o último e mais discriminado na hierarquia social. O moderno coloca o bugre cada vez mais como estrangeiro, pois este, conforme Simmel, é aquele "que, inserido em um círculo, permanece sempre exterior a ele, porque seus atributos não são os mesmos daqueles que caracterizam o círculo" (Waizbort, 1995:75).

As sociedades tradicionais que se modernizaram em alguns aspectos possuem essa idéia do estrangeiro com maior nitidez, como aquele que ao mesmo tempo pertence e não pertence à sociedade, existindo uma tensão entre uma força que o puxa para dentro e uma outra que o joga para fora. Nestas sociedades reinam ainda as relações de mando e obediência, como também existem aquelas consideradas mais democráticas, trazidas pelo próprio desen- 
volvimento. $\mathrm{O}$ horror que as idéias mais democráticas têm da violência das relações mais tradicionais pode colocálas numa posição privilegiada de poder discriminar o outro sem dizer que o está fazendo, pois está a serviço da razão e da verdade. O democrata não consegue perceber as singularidades da pessoa que é chamada de bugre. "Assim o democrata, como o cientista, deixa escapar o singular: o indivíduo não é para ele outra senão uma soma de traços universais" (Sartre, 1960:38). Desta forma, o mais importante para aquele que é chamado de bugre, o reconhecimento de sua especificidade cultural e individual, lhe é negado. Ele é silenciado tanto pelos conservadores, através de uma violência mais explícita, como pelo democrata, através da razão, que não tem olhos para a diferença, na concepção de Sartre.

Resultado de uma história de exclusões e perseguições, o termo bugre carrega hoje uma negatividade muito forte, gerando imagens irreais sobre a realidade daquele que é chamado de bugre.

Não importa o que ele seja realmente, importa, sim, agrupar diversas pessoas, de diferentes procedências, que possuam algumas características em comum, em torno de um mesmo termo, indiferenciando o que é diferenciável.

$\mathrm{Na}$ consciência cacerense, a idéia da infidelidade religiosa presente entre os europeus de outrora perde-se um pouco na história. A sociedade cacerense relaciona o termo em uso corrente com a idéia de infidelidade social, identificando o bugre com aquele que é da fronteira, que possui características indígenas, vagabundo, enfim, aquele que não se coaduna com o ideário produtivista, que vem substituir a visão estritamente religiosa da Idade Média, preservando, porém, sua função moral de justificar a exclusão social do bugre.

\section{BUGRE: UM XINGAMENTO}

De maneira geral, pode-se dizer que existe uma imagem central negativa, de acusação, sobre o bugre com algumas derivações significativas, as quais nos proporciona levantar questões como o porquê de a sociedade cacerense ter a necessidade de construir imagens negativas sobre o bugre e ele a de incorporá-las freqüentemente e quais as conseqüências que estas imagens trazem para a vida cotidiana de uma sociedade.

Num primeiro momento, constata-se, a partir de alguns relatos, o sentido negativo mais amplo que o termo bugre carrega consigo, tendo uma conotação de xingamento. Expressa a condição do outro já caracterizada como ne- gativa, na qual está dada a sua negatividade, irredutível, própria de algo sedimentado, herdado e que perde o seu sentido original, ficando apenas e tão-somente em forma de alcunha. ${ }^{6}$ "(...) o patrão xingava aquele de negro, aquele outro de bugre (...) ele xingava mesmo. Porque lá tinha mais é preto e esses bugres. Na hora que largava de xingar o negro, xingava o bugre, na hora que largava de xingar o bugre, xingava o negro. Aqui o bugre é gente pequena, que é ninguém, um João-Ninguém" (comerciante local).

\section{O CORPO DIFERENTE DO BUGRE}

Os atributos físicos têm grande peso na representação do bugre ${ }^{7}$ e estes aspectos, muitas vezes, são expressos com conotação visivelmente pejorativa. Aqui aparece também a transmissão pelo sangue de características físicas e do comportamento do bugre, aludindo a uma problemática da miscigenação através da sexualidade, projetando o mal no outro, no bugre, que transmite o sangue ruim. "Se ele tiver cabelo liso, ele é bugre, mas se ele tiver o cabelo crespo não se trata de bugre; (...) muitas vezes o pai dele é bugre e a mãe não é, então no caso o cabelo dele já é enrolado, daí ele não é bugre. O meu pai era boliviano, porque veio de Santa Cruz, bem longe lá na Bolívia, aí faz a mistura, o boliviano casa com a brasileira, aí um pouco puxa a mãe e o outro o pai, então o pessoal fala bugre, porque está meio mestiço, misturado o sangue, por isso, por esse lado que eles chamam de bugre" (depoimento do bugre).

A imagem dominante do homem branco faz com que o cacerense retrate a figura do bugre como caricata, esquisita e feia: "A gente conhece o bugre pelo cabelo liso (...) A pele é muito feia. O bugre não é só porque tem o cabelo liso, ele tem o nariz grandão e outros defeitos (...) o bugre (...) é bem moreno, um moreno esquisito, não é preto, é um moreno diferente. (...) Agora, eu nunca vi um bugre bonito, são feios mesmo" (grupo de mulheres cacerenses).

O bugre é visto, aos olhos da cultura branca, como a natureza, como o estado bruto da humanidade que precisa ser lapidado, tendo que ser constantemente dominado e domesticado no contato com o homem branco. Incomoda o cacerense a descaracterização do bugre, mistura de animal e humano, em que "os gêneros e as espécies se confundem momentaneamente" (Medeiros, 1992:15). "Bugre é o nome do cara de beiços grossos, feições grosseiras, às vezes pouca inteligência" (família tradicional local). 
O cacerense, no contato com o nativo da região, esquadrinhou o corpo deste para melhor vigiá-lo no detalhe, verificando suas partes, atitudes e gestos, que fogem à regra, podendo diferenciar-se daquilo que é considerado patológico. Cada característica física do bugre, descrita pelo cacerense, o transforma numa figura distorcida, que foge ao normal. "O normal destaca-se como modelo a ser imitado e a ser interiorizado pelo patológico. Este é reduzido ao silêncio, tanto mais que sua verdade é enunciada pelo normal (...)" (Bruni, 1989a:178).

\section{O BUGRE ÍNDIO: INFERIORIDADE DIANTE DO BRANCO}

Podem ser encontradas imagens mais complexas, superpostas do bugre, com informações a respeito de sua origem étnica, como também tentativas de explicações científicas para a imagem negativa do bugre. Um dos entrevistados afirma categoricamente que o "índio tem uma formação cerebral diferente da do branco", associando esta imagem a descrições físicas do bugre, utilizandose de um discurso mais científico para mostrar o seu preconceito, ou melhor, para escondê-lo. "O bugre mais legítimo tem menos inteligência, assim no tipo de trabalho, não é muito bom de trabalho; eles não gostam de estudar, vai crescendo menos inteligente, mais cabeçudo, a gente enjoa de ensinar e ele não aprende, tem alguns que são fáceis de lidar, agora tem os do mato, a gente vai conversar com eles, a educação deles é diferente, briga com a mulher (...)" (família tradicional local). Desta forma, a ciência assume o papel de definir o que está dentro e o que está fora da normalidade. Outro informante diz que "não é preconceituoso porque se respalda na ciência", instrumentalizando-se com postulados pré-moldados e irredutíveis para dar um único tipo de explicação para o comportamento humano, excluindo a diversidade, o detalhe, o singular em prol do "normal" que submete o diferente. É o discurso de uma ordem e de uma razão deturpadas, proferida pelo homem branco, que cala a diferença. "O colha ${ }^{8}$ é um bugre boliviano, (...) é o cara que eles laçam no meio da mata. Esse cara não sabe falar e é completamente sem cultura. Eles têm uma dificuldade de raciocínio, eles são lentos, eu não sei se eles têm uma deformação neurológica para aprender as coisas, porque eles são um tipo assim; existe um contraponto em que o índio tem uma formação cerebral diferente do branco, isso não é nem preconceito, é científico; o índio, se dá para ele fazer um raciocínio, ele não vai fazer como se deveria fazer, então isso que eles falam lá na Bolívia, o tal do colha, que vive em determinada área" (família tradicional local).

O bugre é descrito de forma caricatural, indicando sua proximidade com a natureza, com o mato, com o escondido, com a solidão, ao contrário do homem da cidade, aquele das multidões, que só se relaciona com a natureza em seu momento de lazer. Talvez seja o medo inconsciente de seu próprio lado bugre, isto é, de sua própria natureza. "Como pode igualar um médico com um braçal, um cientista com um bugre, não tem comparação. Eles não estão inseridos no contexto social, eles não participam do mercado de trabalho, eles não estudam, porque a maioria vive em choças na beira das estradas" (família tradicional local).

Há uma menção ao termo bugre no diminutivo bugrinha, bugrinho -, sendo o "inho(a)" considerado carinhoso, acolhedor, caridoso, reconhecimento da situação de inferioridade em que se encontra o seu portador, necessitando de amparo e proteção. A diferença é vista como desigualdade, como falta de civilização daquele que foge à norma, que foge aos aspectos dominantes da cultura ocidental, evidenciada na aparência física do bugre. “(...) é o tipo bugre, ele surge na cidade, assim ele é bugrinho, o rosto é arredondado, as bochechas arredondadas, meio baixo, a pele bem morena, bem queimada do sol" (família tradicional local).

Assumindo o estigma de menos inteligente atribuído a ele, o bugre procura, afastando-se de sua raiz mais natural e habitual, corresponder ao que a sociedade entende como bom, "normal" e não patológico. "Pretendo estudar, porque aqui é mais fácil, e ser mais inteligente é por isso que eu quis vir para cá, porque é tudo mais fácil. Eu pretendo estudar e trabalhar. Vim com dificuldades, mas a gente não pode ficar com os pais, vim porque sou analfabeta e chega de mato" (bugra).

\section{BUGRE E PATRÃO}

A imagem pejorativa do bugre foi construída fundamentalmente através de sua condição histórica de sujeição e escravidão nas fazendas e em serviços domésticos os mais variados. Agregado a esta imagem, encontramos em Cáceres o hábito de se "pegar para criar algum bugrinho" que, sob o pretexto da caridade, pretende-se, na realidade, ter alguém sob o domínio constante para trabalhar, para servir sempre e a qualquer hora como gratidão ao pai patrão.

Os depoimentos obtidos na pesquisa de campo indicam a existência de condições subumanas em que se en- 
contravam e ainda se encontram os bugres nas relações de trabalho, no controle exarcebado que os fazendeiros tinham sobre os seus corpos, tentando discipliná-los, através do uso da violência física e moral, para a produção. “(...) se você pega uma bugrinha para criar, se você cria ela dando toda consideração, trazendo ela bem arrumadinha, quando ela completar 15 anos, ela foge, vai para casa; agora se você criar ela no chicote, bater mesmo de cortar ela, ela fica a vida inteira trabalhando para você, parece que eles gostam de apanhar, aí eles querem bem, criou judiado pode contar que eles gostam da gente, mas se a gente der valor para eles, eles não reconhecem o valor; as pessoas para criarem bugres, para eles trabalharem, têm que arrochar serviço neles e bater, não deixar eles escutarem conversa de patrão, tem que ser como na escravidão" (filha de fazendeiro).

Em algumas declarações dos bugres, fica evidente a necessidade que eles têm da atenção do patrão, do olhar do patrão, da palavra do patrão, para sentirem-se menos desqualificados do que são; eles se identificam com o patrão, projetando nele aquilo que a realidade lhes nega. "Patrão bom é aquele que a gente tem mais direito de conversar, e o patrão ruim é aquele que passa perto da gente e nem liga, faz de conta que nem conhece" (bugre).

Há dois mundos completamente diversos, um dos fazendeiros, que lembram das festas e da vida farta e ordeira nas fazendas, e o outro dos bugres submetidos à brutalidade física para dar as condições prazerosas tão saudosas dos patrões. Este contraste revela uma sociedade construída sob o signo da violência, na qual o empregado é tratado como animal que deve ser castigado para produzir mais e melhor. "Na Ressaca (fazenda situada na região), por exemplo, tinha a fábrica de pinga, tinha o tronco para estar batendo no empregado todos os dias, tinha a cela também (...) Antigamente os bugres trabalhavam por amor ao trabalho, amor ao patrão; hoje você não pode confiar em quase ninguém" (fazendeiro local).

A sociedade cacerense é o retrato do que ocorreu no Brasil colônia e que ainda ocorre em diversas regiões do país. Hoje, em Cáceres, o bugre representa a história viva dessa violência, símbolo da "exclusão: o lugar mais fundo da sujeição" (Bruni, 1989b:201). A exclusão marcada pelo silêncio daquele que não pode se expressar. Sob a alcunha hoje de vagabundo, selvagem e traiçoeiro, foi ele quem proporcionou as melhores recordações daqueles que o violentaram. "Faziam festa, faziam churrasco, reuniam o povo todo na fazenda do meu pai, tinha tronco, não é bem tronco, é esteio para os empregados que estavam se excedendo na bebida, amarrava ele para evitar desastres; quando você sabe que vai ser amarrado, você evita um pouco" (filha de fazendeiro).

Esta palavra, cujo sentido pejorativo predomina sobre o sentido meramente jocoso, empregada constantemente no cotidiano, aplica-se, na verdade, a uma multiplicidade de etnias, a uma heterogeneidade de culturas, tradições e costumes bastante grande. No seu emprego aleatório, ela opera como fator de desconhecimento de inúmeras diferenças étnicas e culturais. Desta forma, pedir ao bugre que se reconheça numa identidade social "bugre" é cometer outra vez violência contra ele, pois sua identidade foi, há séculos, submetida a um processo insidioso de dissolução e destruição.

O que aparece claramente é que está sempre em funcionamento um processo de atribuição de identidade realizada inteiramente pelo outro. As demonstrações de aceitação da identidade "bugre" parecem muito mais sinais de assimilação social do que propriamente afirmação autônoma de si.

Talvez as técnicas de pesquisa de campo utilizadas não tenham sido favoráveis à apreensão dessa identidade própria que, como visto, é múltipla. O que a pesquisa revela é a assimilação de parte dessa população que continua ao mesmo tempo discriminada e excluída: os bugres migram do campo para a cidade para encontrarem trabalho na economia formal, aumentarem seu grau de escolaridade e serem aceitos por sua qualificação profissional. Entretanto, essa pequena parcela do grupo não consegue esconder a imensa maioria que vive de forma extremamente humilde, apagada e sofrida.

Nas entrevistas, também não se observa menção aos seus próprios desejos, interesses, expectativas e direitos. Não há menção a nenhuma instância de representação seja ela política, social ou cultural. Os bugres, inteiramente abandonados a seus próprios corpos, são, como disse um dos entrevistados, "ninguém, um João-Ninguém"!

\footnotetext{
NOTAS

E-mail do autor: lguisard@ seade.gov.br

1. O conteúdo foi extraído de Dissertação de Mestrado (Guisard, 1996).

2. Sobre o bogomilismo consultar o trabalho de Queiroz (1988:24-28). Existe uma imensa bibliografia a respeito. Ver também Monsenhor Cristiani (1962).

3. Sobre o movimento dos paulacianos, consultar o trabalho de Abramson, Gurevitch e Kolesnitski (1978).

4. Sobre a origem do termo bugre, consultar os trabalhos: Littré (1801-1881); Enciclopédia Italiana (1949); Bueno (1968); Guérios (1979); Abramson, Gurevitch e Kolesnitski (1978).
} 
5. Goffman (1978:12) estudou a lógica estrutural do estigma na relação interindividual, tendo como referência especialmente a sociedade americana atual. "Enquanto o estranho está à nossa frente, podem surgir evidências de que ele tem um atributo numa categoria em que pudesse ser incluído, sendo até, de uma espécie menos desejável - num caso extremo, uma pessoa completamente má, perigosa ou fraca. Assim, deixamos de considerá-lo criatura comum e total, reduzindo-o a uma pessoa estragada e diminuída. Tal característica é um estigma". Procurou-se neste artigo, evidenciar a história do estigma, isto é, as camadas de significações sucessivas que, agregadas, vão constituindo o estereótipo. 6. "As alcunhas são as ferramentas necessárias e portáteis, com as quais se pode simplificar o processo de causar dano a alguém, realizando o trabalho no menor prazo e com o menor número de embaraços possíveis. Essas palavras ignominiosas, vis, desprovidas de significado real, irritantes e envenenadas, são os sinais convencionais com que se etiquetam, se marcam, se classificam os vários compartimentos da sociedade para regalo de uns e animadversão de outros. As alcunhas são concebidas para serem usadas já prontas, como frases feitas; de todas as espécies e todos os tamanhos, no atacado ou no varejo, para exportação ou para consumo interno e em todas as ocasiões da vida (...)" (Hazlitt apud Chauí, 1989:48).

7. "O homem branco desfrutou durante três mil anos o privilégio de ver sem que o vissem; era puro olhar, a luz de seus olhos subtraía todas as coisas da sombra natal, a brancura de sua pele também era um olhar, de luz condensada. O homem branco, branco porque era homem, branco como o dia, branco como a verdade, branco como a virtude, iluminava a criação qual uma rocha, desvelava a essência secreta e branca dos seres (...)" (Sartre, 1960:105).

8. Colha é o bugre chiquitano, da Província de Chiquitos, Bolívia (nota do autor)

\section{REFERÊNCIAS BIBLIOGRÁFICAS}

ABRAMSON, M.; GUREVITCH, A. e KOLESNITSKI. História da Idade Média. A Alta Idade Média. Lisboa, 1978.

BRUNI, J.C. Poder e ordem social na obra de Auguste Comte. Tese de Doutorado. São Paulo, FFLCH/USP, 1989a.

"Foucault: o silêncio dos sujeitos". Tempo Social. São Paulo, USP, v.1, n.1, 1ํs. sem. 1989b, p.199-207.
BUENO, F. da S. Grande Dicionário Etimológico-Prosódico da Língua Portuguesa. São Paulo, Saraiva, 1968.

CHAUÍ, M. "Produtividade e humanidades". Tempo Social. São Paulo, USP, v.1, n.2, 1989, p.45-71.

ENCICLOPÉDIA ITALIANA. Instituto Della Enciclopédia Italiana, Fondata da Giovanni Treccani, 1949.

FERNANDES, H.R. Sintoma social dominante e moralização infantil. São Paulo, Escuta, 1994.

FREUD, S. O “estranho". Obras Psicológicas Completas. Rio de Janeiro, Imago Ed., v.XVII, 1976.

FREYRE, G. Casa grande e senzala. Brasília, Editora Universidade de Brasília, 1963.

GOFFMAN, E. Estigma, notas sobre a manipulação da identidade deteriorada. Rio de Janeiro, Zahar Editores, 1978.

GUÉRIOS, R.F.M. Dicionários de Etimologias da Língua Portuguesa. São Paulo, Cia. Editora Nacional, 1979.

GUISARD, L.A. de M. O bugre: um João-Ninguém. Estudo sobre exclusão social em Cáceres - MT. Dissertação de Mestrado. São Paulo, Universidade de São Paulo, Faculdade de Filosofia, Letras e Ciências Humanas, 1996.

LITTRÉ, P.É. Dictionnaire de la Langue Française. Livr. Hachrtte, 1801-1881.

MEDEIROS, S.L.R. "Manoel de Barros: o poeta que responde com poesia”. Jornal da USP. São Paulo, Ano VI, n.213, 27/05/92.

MONSENHOR CRISTIANI. Breve história das heresias. São Paulo, Flamboyant, 1962.

QUEIROZ, T.A.P. de. As heresias medievais. São Paulo, Atual, 1988.

SARTRE, J.-P. Reflexões sobre o racismo. São Paulo, Difusão Européia do Livro, 1960.

. A imaginação. São Paulo, Difusão Européia do Livro, 1964

SCHWARCZ, L.M. O espetáculo das raças. Cientistas, instituições e questão racial no Brasil, 1870-1930. São Paulo, Companhia das Letras, 1993.

UNIVERSIDADE FEDERAL DE MATO GROSSO. Fundação de Vila Maria. Cáceres. Mato Grosso, UFMT, s/d.

WAIZBORT, L. "Georg Simmel e o judaísmo. Entre a emancipação e a assimilação". Revista Brasileira de Ciências Sociais. Anpocs, n.27, ano 10, fev. 1995 